\title{
Effect of high-voltage electrical stimulation on the albumin and histamine serum concentrations, edema, and pain in acute joint inflammation of rats
}

\author{
Maria C. Sandoval $^{1 \dagger}$, Carolina R. Ramirez ${ }^{1}$, Diana M. Camargo ${ }^{1}$, \\ Thiago L. Russo², Tania F. Salvini ${ }^{2}$
}

\begin{abstract}
Background: The mechanism by which high-voltage electrical stimulation (HVPC) acts on edema reduction is unknown. Objective: To assess the effect of HVPC with negative polarity (-) applied to the ankle of rats with acute joint inflammation. Method: Sixty-four rats were divided into four groups ( $\mathrm{n}=16)$ : inflamed+HVPC(-), $0.03 \mathrm{~mL}$ application of t-carrageenan $(3 \%)$ to the tibiotarsal joint plus HVPC(-); inflamed+HVPC placebo, carrageenan application and HVPC placebo; normal+HVPC(-), HVPC application(-); and normal control, no intervention. The HVPC(-) $100 \mathrm{~Hz}$ at a submotor level was applied daily for $45 \mathrm{~min}$ on three consecutive days. The variables were pain, hind-foot volume, and serum histamine and albumin assessed before and during the 48 hours following inflammation. The variables were compared using the $t$ test, one-way ANOVA, nested ANOVA for repeated measures, and the post hoc Bonferroni test. Analysis of covariance was applied to adjust the effects of HVPC(-) by measurements of pain, inflammation, albumin, and histamine at $24 \mathrm{~h}$, and the final weight was compared to the other groups. The significance level was set at $\mathrm{p}<0.05$. Results: There were no differences between the inflamed+HVPC(-) and inflamed+HVPC placebo groups in terms of pain or edema $(p>0.05)$. Albumin was reduced in the groups that received the intervention, but there was no differences between them. There was only a 24 hour increase in histamine with the normal $+\mathrm{HVPC}(-)(\mathrm{p}=0.0001)$ and inflamed $+\mathrm{HVPC}$ placebo groups $(\mathrm{p}=0.01)$ compared to the normal control group. Conclusions: The results of the present study suggest that HVPC(-) with the parameters employed did not reduce pain or edema and did not change serum albumin or histamine levels, which indicates the inability of this resource to have a positive effect when treating treat acute joint inflammation.
\end{abstract}

Keywords: physical therapy; electrical stimulation; sprain; inflammation.

\section{HOW TO CITE THIS ARTICLE}

Sandoval MC, Ramirez CR, Camargo DM, Russo TL, Salvini TF. Effect of high-voltage electrical stimulation on the albumin and histamine serum concentrations, edema, and pain in acute joint inflammation of rats. Braz J Phys Ther. 2015 Mar-Apr; 19(2):89-96. http://dx.doi.org/10.1590/bjpt-rbf.2014.0079

\section{Introduction}

The individual's ability to return to normal activity in the presence of joint inflammation often depends on the reduction of pain and edema ${ }^{1,2}$. Therefore, the control of pain and edema are essential for a quick recovery of musculoskeletal function.

High-voltage electrical stimulation (high-voltage pulsed current - HVPC) is one of the treatments used in physical therapy to control these symptoms. HVPC is a monophasic pulsed electric current that consists of double-peaked impulses with a very short duration (5-100 $\mu \mathrm{s})$ and longer interpulse intervals, which generates a low total current $(1.5 \mathrm{~mA})$, despite a voltage greater than $150 \mathrm{~V}$. It has been reported that in animals, the use of the monophasic current ${ }^{3}$ with negative polarity (-) and a submotor level of stimulation $^{4-8}$ reduces acute post-traumatic edema ${ }^{3,4}$.
Other studies using low-voltage current ${ }^{9}$ with positive polarity ${ }^{10}$ and motor-level stimulation ${ }^{11}$ have shown no reduction in edema. To our knowledge, only one study has demonstrated clinical differences in the reduction of chronic post-traumatic hand edema in humans ${ }^{1}$.

The mechanisms by which HVPC(-) acts to decrease edema have not been extensively studied, and several hypotheses have been proposed. One of these hypotheses is the electrophysiological phenomenon described by Cosgrove et al. ${ }^{12}$ that assumes that the HVPC(-) repels the proteins, causing their displacement in the interstitium of the traumatized area, accelerating protein uptake by the lymphatic capillaries, which, in turn, facilitates lymphatic flow and decreases the interstitial oncotic pressure and edema. This hypothesis was partially supported by Reed ${ }^{13}$, who reported that

\footnotetext{
In Memorian

${ }^{1}$ Escola de Fisioterapia, Universidade Industrial de Santander (UIS), Bucaramanga, Colômbia

${ }^{2}$ Departamento de Fisioterapia, Universidade Federal de São Carlos (UFSCar), São Carlos, SP, Brazil

Received: Mar. 13, 2014 Revised: Sept. 16, 2014 Accepted: Oct. 21, 2014
} 
HVPC(-) at 30 and $50 \mathrm{~V}$ significantly decreased the permeability to the macromolecules, and then limited the edema formation, particularly in the acute phase. Another hypothesis suggested that HVPC(-) stimulated lymphatic flow and then facilitated its drainage ${ }^{5,14}$. Based on the hypothesis of Cosgrove et al. ${ }^{12}$, Cook et al. ${ }^{15}$ suggested that HVPC(-) facilitated albumin transport, increasing its movement, which then increased the diameter of lymphatic lumen and caused contraction of lymphatic smooth muscle. Karnes et al. ${ }^{9}$ proposed other hypotheses: 1) HVPC(-) contracted the smooth muscle surrounding blood vessels, decreasing the diameter of arterioles; 2) because HVPC(-) is polarized, it generated the accumulation of electric charges, which then changed the $\mathrm{pH}$ and decreased the edema.

Taylor et al. ${ }^{3}$ also reported that HVPC(-) reduced the diameter of arterioles and thereby reduced the blood flow, which might be another mechanism of action. Therefore, HVPC(-) could either influence histamine release from cells or affect the histamine-binding site of the histamine receptors in the postcapillary-venule endothelial cells. These hypotheses hold that albumin and histamine were important for the positive effects of HVPC(-). Albumin accounts for $50 \%$ of total plasma protein and is responsible for $75 \%$ of the colloid osmotic pressure ${ }^{16}$. Histamine is a dibasic vasoactive amine secreted at the beginning of the inflammation process. It causes arteriolar dilation, increasing the vascular permeability of the large venules, which then allows the movement of fluid and proteins into the extravascular space ${ }^{17}$. Therefore, albumin and histamine are important inflammation markers.

Based on this background, the hypothesis of the present study was that HVPC(-) decreased edema and the production of histamine and reduced the movement of albumin into the interstitial space, as a result of reduced endothelial permeability. The present study aimed to assess the effect HVPC(-) applied to the rat ankle on pain, edema, and serum levels of albumin and histamine in acute joint inflammation.

\section{Method}

\section{Animals}

Sixty-four male Wistar rats (311.5 $\pm 36.1 \mathrm{~g})$ were kept in plastic cages (four animals per cage), with water and pelleted food ad libitum. They were maintained in a controlled environment with a 12:12 h light-dark cycle and temperature of $22 \pm 2^{\circ} \mathrm{C}$. At the end of the experimental protocol (48 hours), the animals were killed by anesthetic overdose. This study was approved by the Animal Experimentation Ethics Committee of the Universidade Federal de São Carlos (UFSCar), São Carlos, SP, Brazil (No. 027/2007).

\section{Experimental groups}

The animals were randomly divided into four groups (16 animals per group).

Inflamed+HVPC(-) group: animals received an injection of 1 -carrageenan in the ankle of the right paw, followed by immediate application of HVPC(-).

Inflamed + HVPC Sham group: animals received an injection of 1 -carrageenan, followed by the placement of the HVPC electrodes, but without the application of the current.

Normal+HVPC(-) group: animals were submitted to HVPC(-) with the same parameters used in the intervention group.

Normal control group (NCG): this group received no intervention.

The animals were weighed before and after the experiment. For all experimental procedures and euthanasia, animals were anesthetized through intraperitoneal injection of a cocktail containing xylazine $(12 \mathrm{mg} / \mathrm{kg})$ and ketamine $(95 \mathrm{mg} / \mathrm{kg})$. The dorsal region of the trunk and both hind legs were shaved to visualize the sites of carrageenan injection and electrode placement.

\section{Joint inflammation procedure}

The inflammation was induced in the right tibiotarsal joint by an injection of $0.03 \mathrm{~mL}$ of $3 \%$ t-carrageenan (Sigma Chemical Company, St. Louis, USA) dissolved in saline solution $(0.9 \% \mathrm{NaCl})$. The administration followed the method described by Omote et al. ${ }^{18}$. All joint inflammation was induced in the morning.

Volume assessment: Volumetry was used to assess the volume, which is considered a gold-standard method with high reproducibility (intraclass correlation coefficient $(\mathrm{ICC})=0.99)$ and an error less than $1 \%{ }^{19}$. A glass cup constructed especially to fit the animal paw (5 $\mathrm{cm}$ high and $4 \mathrm{~cm}$ in diameter) was used. It had been previously evaluated to ensure reproducibility in the volume measurements $(\mathrm{ICC}=0.95)$. For the measurements, the lateral region of the rat's ankle was marked, measuring $1 \mathrm{~cm}$ from the base of the heel. Following the ankle marking, the animal was suspended in a sling similar to that used by Dolan et al. ${ }^{6,7}$ in their studies. Water was placed in the cup to the maximum level, allowing the liquid leakage to stabilize. Then, the paw was immersed up to the level of the paw's ink mark. The displaced water was collected and 
measured, where $1 \mathrm{~mL}=1 \mathrm{mg}$. This measurement was performed before the application of carrageenan, as well as 5, 24, and 48 hours after the induction of inflammation.

Pain evaluation: A paw withdrawal latency to radiant heat was used ${ }^{20-23}$, which is a method with high reproducibility $(\mathrm{r} 2=0.78) 23$. The animal was placed in a glass box $(20 \mathrm{~cm}$ long, $15 \mathrm{~cm}$ wide, $15 \mathrm{~cm}$ high), which was maintained on an elevated platform with a lamp under the right paw. After 10 minutes of acclimation, the lamp and the timer were simultaneously turned on, and the time at which the animal withdrew its paw from the bottom of the box was recorded (in seconds); this interval was noted as the paw withdrawal latency $(\mathrm{PWL})^{20}$. This assessment was repeated three times with 5 minutes of rest between each measurement. The median of the values obtained in the three assessments was calculated. The PWL was assessed 12 hours before starting the experiment and 6,24, and 48 hours after the induction of inflammation. Pain was assessed 1 hour after measuring paw volume because the animal needed to be awake for the test.

Serum levels of albumin and histamine: Two milliliters of blood was collected from the animals of the electrically stimulated and placebo groups 24 and 48 hours after injection of carrageenan. Only one collection was performed in the NCG group. Blood was collected from 8 of the 16 animals in each group. The first blood sample was collected from the tail vein, and the second sample was collected from the renal artery. Albumin was processed using the bromocresol green method $^{24}$ and quantified in a spectrophotometer at a wavelength of $630 \mathrm{~nm}$. Histamine was measured by radioimmunoassay ${ }^{24}$.

Volume and pain assessment and blood collection were performed between 8 am and 2 pm, according to the time that inflammation was induced in each animal.

\section{HVPC protocol}

HVPC was applied with a Neurodyn High Volt (Ibramed, Brazil), with current characterized by doublepeak monophasic pulses. The HVPC protocol was as follows: pulse duration of $20 \mu \mathrm{s}$, interpulse interval of $100 \mu \mathrm{s}$, frequency of $100 \mathrm{pps}$, and amplitude at a submotor level. The pressure was gradually increased until a visible twitch was observed, and then it was decreased to a threshold immediately below the muscle contraction. Negative polarity was used with two square, active, self-adhesive electrodes $\left(1 \mathrm{~cm}^{2}\right)$, attached with adhesive tape on the lateral and medial regions of the tibiotarsal joint ${ }^{1}$. A rectangular dispersive self-adhesive electrode $(9 \times 3 \mathrm{~cm})$ was maintained in the dorsal region of the animal's trunk. During the application of current, the animals were kept in a warm environment to prevent hypothermia caused by anesthesia. The inflamed+HVPC(-) group and the inflamed+HVPC Sham group were submitted to the HVPC treatment immediately after the carrageenan injection, while the normal+HVPC(-) group was submitted to this treatment after shaving. All animals received a daily session of electrical stimulation or Sham for 45 minutes on three consecutive days.

\section{Statistical analysis}

The paired student's t-test was used to determine possible differences (i.e. initial vs. final) in weight, histamine, and albumin between groups of animals; the percentage of weight variation was also determined [i.e. (final mass x 100)/initial mass]. One-way analysis of variance (ANOVA) was used to describe and compare the variables between the groups, and the post hoc Bonferroni test was applied when differences were observed. The Kruskal-Wallis test was used to determine the differences in the variable pain between groups. Repeated-measures ANOVA (i.e. nested ANOVA) was used to analyze the volume and pain values obtained at different times. In addition, analysis of covariance was used for the output variables (i.e. pain, inflammation, histamine, and albumin) 48 hours after the induction of inflammation to evaluate the differences between the inflamed+HVPC(-) group and the other groups. With this analysis, the results were adjusted by the measurements performed at $0,5,6$, and 24 hours, as well as by the initial and final weight of the animals. The data were processed with STATA 9.0 software. The significance level was set at $\mathrm{p}<0.05$.

\section{Results}

\section{Body weight}

In all groups, there was a difference between the initial and the final weight. The three groups that received intervention presented weight loss, which was greater in the inflamed+HVPC(-) group (Table 1).

\section{Pain}

No significant differences were observed in PWL between groups at any time-point (Table 2). Similarly, no significant differences were observed in the PWL between the beginning and end of the experiment in any group (Table 2). Additionally, there were no 
differences by treatment or by time-point $(\mathrm{p}=0.09$ and $\mathrm{p}=0.33$, respectively).

\section{Volume}

All groups showed similar paw volume at baseline $(p=0.65)$. There was a significant increase in paw volume 24 hours after the induction of inflammation compared with baseline in the inflamed+HVPC(-) and inflamed+HVPC placebo groups, and this difference was also observed at 48 hours. However, there was no difference between these two groups in any of the analyzed time-points. There were no differences by treatment $(\mathrm{p}=0.22)$ or by time-point $(\mathrm{p}=0.057)$.

\section{Albumin}

There was no difference in serum albumin at 24 hours between the groups $(\mathrm{p}=0.34)$. Serum albumin was lower at 24 than at 48 hours in the normal+HVPC(-), inflamed+HVPC placebo, and inflamed + HVPC(-) groups, with no difference between these groups $(\mathrm{p}=0.89$; Table 3$)$.

\section{Histamine}

Serum histamine was different between the groups at 24 hours ( $\mathrm{p}=0.006$; Table 4). However, only the normal+HVPC(-) and inflamed+HVPC placebo groups presented a significant increase in histamine compared with NCG ( $p=0.001$ and $p=0.01$, respectively). At 48 hours, a reduction in histamine was observed in the three groups that received intervention (Table 4). However, for the normal+HVPC(-) group, this difference was significant $(\mathrm{p}<0.0001)$ only when compared with the value obtained at 24 hours (Table 4). There was no difference in serum histamine between the three experimental groups at 48 hours $(\mathrm{p}=0.20$; Table 4$)$. However, the inflamed+HVPC(-) group presented the lowest histamine (Table 4).

\section{Analysis of covariance}

The analysis of the effect of HVPC(-) in the inflamed group on PWL revealed a positive association $\beta=5.84$ $(\mathrm{p}=0.08)$ compared with the normal+HVPC(-) group. This coefficient was adjusted by PWL measurements 24 hours after induction of inflammation, by histamine and albumin at 48 hours, and by the final weight of the experimental animals. The effect of HVPC(-) on histamine presented a $\beta=1.97(\mathrm{p}=0.42)$, similar to the inflamed+HVPC Sham group $(\beta=1.84 ; \mathrm{p}=0.43)$. These results were adjusted by the histamine measurements 24 hours after induction of inflammation, and also by measurements of pain, inflammation, and albumin 48 hours after induction of inflammation and the final weight of the animals (Table 5).

Table 1. Comparison between initial and final mass within each group of mice (mean $\pm \mathrm{SD}$ ).

\begin{tabular}{lcccc}
\hline & Normal Control & Normal+ HVPC(-) & $\begin{array}{c}\text { Inflamed+ } \\
\text { HVPC Sham }\end{array}$ & Inflamed + HVPC(-) \\
Initial mass (g) & $283.4 \pm 34.2$ & $327.1 \pm 35.3$ & $324.6 \pm 32.9$ & $310.9 \pm 26.4$ \\
Final mass (g) & $291.9 \pm 35.6$ & $316.1 \pm 31.7$ & $308.2 \pm 30.8$ & $289.6 \pm 23 *$ \\
p (initial vs. final) & $<0.0001$ & $<0.0001$ & $<0.0001$ & $<0.0001$ \\
$\%$ variation & $+3 \%$ & $3.38 \%$ & $5.05 \%$ & $6.9 \%$ \\
\hline
\end{tabular}

${ }^{*} \mathrm{p}<0.05$ compared to normal+ HVPC(-) \% variation:[ (final mass x 100)/initial mass)]. HVPC: High voltage electrical stimulation; : statistical significance

Table 2. Paw withdrawal latency time over the course of 48 hours within each group of mice.

$\begin{array}{ccccc}\begin{array}{c}\text { Test } \\ \text { Time }\end{array} & \text { Normal Control } & \text { Normal + HVPC(-) } & \begin{array}{c}\text { Inflamed + } \\ \text { HVPC Sham }\end{array} & \begin{array}{c}\text { Inflamed + } \\ \text { HVPC(-) }\end{array} \\ 0 & 26.5[19-40] \mathrm{s} & 37.5[18-64] \mathrm{s} & 25.5[16-34] \mathrm{s} & 31.5[24.5-51] \mathrm{s} \\ \text { (between groups) }\end{array}$

Data are presented as median \pm [Standard Deviation]. HVPC: High voltage electrical stimulation; S: seconds. P: statistical significance. 
Table 3. Comparison of albumin $(\mathrm{g} / \mathrm{dL})$ between 24 and 48 hours within each group of mice.

\begin{tabular}{ccccc}
\hline Time & $\begin{array}{c}\text { Normal } \\
\text { Control }\end{array}$ & $\begin{array}{c}\text { Normal + } \\
\text { HVPC(-) }\end{array}$ & $\begin{array}{c}\text { Inflamed + } \\
\text { HVPC Sham }\end{array}$ & $\begin{array}{c}\text { Inflamed+ } \\
\text { HVPC(-) }\end{array}$ \\
$24 \mathrm{~h}$ & $2.52 \pm 0.54$ & $2.76 \pm 0.24$ & $2.83 \pm 0.37$ & $2.8 \pm 0.3$ \\
$48 \mathrm{~h}$ & & $2.46 \pm 0.29^{*}$ & $2.34 \pm 0.2^{*}$ & $2.3 \pm 0.33^{*}$ \\
$\mathrm{p}(24 \mathrm{vs} .48 \mathrm{~h})$ & & 0.03 & $<0.0001$ & 0.004 \\
\hline
\end{tabular}

Data are expressed as the mean $\pm \mathrm{SD}$. ${ }^{*} \mathrm{p}<0.05$ compared to their respective values at 24 hours. HVPC: High voltage electrical stimulation. P: statistical significance

Table 4. Comparison of histamine (nmol/L) between 24 and 48 hours within each group of mice.

\begin{tabular}{ccccc}
\hline Time & $\begin{array}{c}\text { Normal } \\
\text { Control }\end{array}$ & $\begin{array}{c}\text { Normal + } \\
\text { HVPC(-) }\end{array}$ & $\begin{array}{c}\text { Inflamed + } \\
\text { HVPC Sham }\end{array}$ & $\begin{array}{c}\text { Inflamed+ } \\
\text { HVPC(-) }\end{array}$ \\
$24 \mathrm{~h}$ & $3.09 \pm 3.31$ & $9.25 \pm 3.01^{*}$ & $8.34 \pm 3.9^{*}$ & $5.68 \pm 2.68$ \\
$48 \mathrm{~h}$ & & $6.64 \pm 2.76^{* *}$ & $5.16 \pm 2.62$ & $3.9 \pm 1.15$ \\
$\mathrm{p}(24 \mathrm{vs} .48 \mathrm{~h})$ & & $<0.0001$ & 0.18 & 0.30 \\
\hline
\end{tabular}

Data are expressed as the mean $\pm \mathrm{SD} .{ }^{*} p<0.05$ compared to normal control; $* *_{\mathrm{p}}<0.01$ compared to normal control. HVPC: high voltage electrical stimulation; p: statistical significance.

Table 5. Analysis of covariance for dependent variables. Comparison group: Normal+HVPC(-).

\begin{tabular}{lcc}
\hline \multicolumn{1}{c}{ Variable } & Inflamed + HVPC Sham Placebo & Inflamed + HVPC(-) \\
PWL time (s) $48 \mathrm{~h}$ & $\boldsymbol{\beta}(\mathbf{p})$ & $\boldsymbol{\beta}(\mathbf{p})$ \\
Volume $(\mathrm{mL}) 48 \mathrm{~h}$ & ---- & $5.84(0.08)$ \\
Albumin $(\mathrm{g} / \mathrm{dL}) 48 \mathrm{~h}$ & ---- & $-0.35(0.24)$ \\
Histamine $(\mathrm{nmol} / \mathrm{L}) 48 \mathrm{~h}$ & $-0.09(0.58)$ & $-0.18(0.41)$ \\
\hline
\end{tabular}

HVPC: high voltage electrical stimulation; PWL: paw withdrawal latency time. s: seconds; h: hours; mL: millilitres; B: association; $\mathrm{p}$ : statistical significance; g/dL: grams/deciliters; nmol/L: nanomol/liter.

\section{Discussion}

HVPC(-) applied at a submotor level 45 minutes per day for three consecutive days was not effective in reducing pain or edema in the joint inflammation induced by 1 -carrageenan. Furthermore, analysis of covariance, adjusted by PWL measured 24 hours after induction of inflammation, by the final weight of the animal, and by albumin and histamine levels 48 hours after induction of inflammation, demonstrated a positive association $(\beta=5.84)$ with borderline significance, indicating increased pain in the inflamed+HVPC(-) group. These results are exciting because several of the parameters used are similar to those used in previous studies $^{1,4-8,10,11,13-15}$, which allowed for comparisons.

Carrageenan injection is an inflammatory model frequently used in animals to assess the inflammatory process and the effectiveness of drugs and physical resources in the inflammation and pain treatment ${ }^{25,26}$. 1-Carrageenan sensitizes the primary afferents and generates primary hyperalgesia in the injury $\operatorname{site}^{27}$. Next, there is a high production of nitric oxide, prostaglandins, free radicals, and cyclooxygenases that activate the dorsal horn neurons, generating a central sensitization, spinal or supraspinal, which in combination with an increased sensitivity of peripheral nociceptors is manifested as a secondary hyperalgesia ${ }^{27}$. Using the same experimental model, Sluka et al. ${ }^{21}$ and Resende et al. ${ }^{26}$ showed reduced primary hyperalgesia by applying high-frequency transcutaneous electrical nerve stimulation (TENS) (100 $\mathrm{Hz}$ and $130 \mathrm{~Hz}$, respectively), similar to that used in the present study. Our results show that the inflamed+HVPC placebo group presented the lowest PWL, and the inflamed+HVPC(-) group presented longer PWL, though without a significant difference. These results indicate that HVPC(-) may increase the threshold of excitability in the primary afferent neurons and help control the pain. A possible cause of the lack of significance in the PWL values could be the short duration of the HVPC pulse, which did not allow for the stimulation of the A $\delta$ receptors or inhibition of the medullary dorsal horn neurons ${ }^{26}$. 
The inflammatory process induced by carrageenan observed in the present study was similar to previous studies $^{20,22,23,27}$. These studies reported the presence of pain and edema in the first 5 hours, which persisted for up to 24 hours and then decreased. In our study, HVPC(-) did not promote greater reduction of edema in the inflamed+HVPC(-) group. Accordingly, our results are not in agreement with those obtained in previous studies that demonstrated significant differences in the reduction of trauma-induced edema in rats ${ }^{3-8,13}$. Perhaps the mechanisms of the induction of inflammation (carrageenan versus trauma) influenced these different results.

The HVPC parameters used in the present study are the same as in previous studies regarding the type of current ${ }^{1,4-8,10,11,13-15}$, level of stimulation ${ }^{4-8,15}$, polarity $1,4-8,10,11,13-15$, and frequency, as well as the application of the stimulation immediately after the induction of inflammation. The differences in our protocol were the mechanism of injury and the duration of the current.

Previous studies ${ }^{3-8,13}$ have used a traumatic incident to generate the inflammation, while the administration of carrageenan was the choice in the current study. Carrageenan induces inflammation and particularly produces the presence of polymorphonuclear cells in the synovial fluid during the acute phase, followed by proliferation and infiltration of the synovial membrane; the number of cells in the synovial fluid gradually decreases 24 hours after the inflammation induction $^{28}$. This model was chosen because it produces a homogeneous pattern in the involvement of soft and joint tissues. This homogeneous pattern of inflammation between the animals cannot be guaranteed in models using mechanical trauma because the joint is injured by hitting the paw, without ensuring the generation of a controlled joint inflammation. Furthermore, the carrageenan model is a validated model for studying the inflammatory process ${ }^{25,26}$. Our results indicate that HVPC(-) was not effective at controlling the inflammatory process induced by carrageenan, possibly due to the involvement of the cartilage and synovial tissue, as well the parameters used, which will be discussed below. Further studies should be conducted to assess the articular cartilage and the presence of circulating inflammatory cytokines, such as IL-6 and TNF- $\alpha$.

The present study used a 45-minutes session of HVPC(-) on three consecutive days in an attempt to mimic what is performed in the clinical practice. Previous studies ${ }^{4,6-8}$ that reported a decrease in edema applied three or four 30-minute applications on the same day that the lesion was established (i.e. 1.5 to 2 hours per day) with a 30-minute rest between the applications. An increase in edema was observed in the periods of non-intervention. Compared to our study, these results indicate that the duration of the application can be critical in reducing edema, as proposed by Mendel and Fish ${ }^{29}$, who suggested the use of longer applications during the acute stage of inflammation. Future studies in humans should assess the effect of the duration of the HVPC(-) application on acute inflammation.

Albumin was reduced in the groups submitted to inflammation at 48 hours. The acute inflammatory phase generated by carrageenan is characterized by an increase in circulating cytokines, such as IL-1, IL- 6 and TNF $\alpha$, which produce two effects 31 . The first effect is the increased microvascular permeability that allows a large loss of plasma proteins, which accumulate in the interstitial space. The second effect is a reduced synthesis and release of negative acute phase proteins, such as ferritin and albumin ${ }^{28}$. These factors result in hypoalbuminemia, which was observed 48 hours after induction of inflammation, especially in the animals submitted to inflammation.

On the other hand, a less strong response was found in the animals from the normal+HVPC(-) group, which can be explained by the reduction in plasma volume and anesthesia, in agreement with the study conducted by Renkin et al. ${ }^{30}$. Another factor that may have influenced the decrease in albumin was the weight loss observed in the animals. There was no difference in albumin level between the two inflammation groups, which is consistent with previous studies addressing paw volume and indicates no effect of HVPC(-) on the permeability of the endothelium. One possible explanation is that the short pulse duration was not able to generate plasma protein movement, as suggested by Mendel and Fish ${ }^{29}$.

Plasma histamine was selected due to its importance as a mediator of acute inflammation. Furthermore, the local administration of carrageenan produces a systemic reaction in response to local inflammation, which is consistent with an acute-phase response ${ }^{31}$. Differences were observed in serum histamine between the inflamed + HVPC placebo group and normal + HVPC(-) groups compared to the normal control group 24 hours after the beginning of the experiment; the higher increase was observed in the normal+HVPC(-) group. Two previous studies ${ }^{32,33}$ have reported an increase in the histamine precursor histidine decarboxylase in skeletal muscle after direct application of HVPC that 
peaks 8 to 12 hours after the stimulation. The increase in histamine precursor depended on the intensity and duration of the stimulation ${ }^{32}$. This pro-inflammatory effect may be associated with the local stress produced by the current and with the metabolic changes at the application site. Further studies are needed to confirm these hypotheses.

However, the histamine levels observed in the animals from the inflamed+HVPC group were not significantly different from the other groups 24 and 48 hours after induction of inflammation. Similarly, the analysis of covariance did not reveal significant differences (Table 5). This result indicates that during the acute phase of the inflammatory process, HVPC(-) was not able to regulate histamine release or affect the histamine binding sites in the postcapillary venule endothelial cells, which is contrary to the hypothesis proposed by Taylor et al. ${ }^{3}$. However, the histamine levels observed in the inflamed+HVPC(-) group 24 and 48 hours after induction of inflammation were lower than the ones observed in the inflamed+placebo group, suggesting that electrical stimulation could help control inflammation even with no change in clinical parameters, such as edema. Therefore, further studies should address more sensitive markers of inflammation, such as TNF $\alpha$ or IL-1.

\section{Clinical implications}

Although the HVPC(-) was not effective, at a significance level of $p<0.05$, this current influenced the release of mediators such as histamine as well as the PWL in animals submitted to HVPC(-). Furthermore, HVPC(-) promoted an increase in histamine in normal animals. However, it is necessary to analyze the physiological implications of these results and also whether they also occur in humans.

\section{Conclusions}

HVPC(-) with the parameters used in this study and applied in the acute phase of joint inflammation induced by carrageenan can regulate histamine and increase the PWL. However, it was not effective at reducing edema. Further studies are needed to validate the use of HVPC(-) in the treatment of acute inflammation.

\section{References}

1. Griffin JW, Newsome LS, Stralka SW, Wright PE. Reduction of chronic posttraumatic hand edema: a comparison of high voltage pulsed current, intermittent pneumatic compression, and placebo treatments. Phys Ther. 1990;70(5):279-86. PMid:2185495.
2. Nelson RM, Hayes KW, Currier DP. Clinical electrotherapy. USA: Appleton \& Lange; 1999.

3. Taylor K, Mendel FC, Fish DR, Hard R, Burton HW. Effect of high-voltage pulsed current and alternating current on macromolecular leakage in hamster cheek pouch microcirculation. Phys Ther. 1997;77(12):1729-40. PMid:9413451.

4. Bettany JA, Fish DR, Mendel FC. Influence of high voltage pulsed direct current on edema formation following impact injury. Phys Ther. 1990;70(4):219-24. PMid:2315384.

5. Taylor K, Fish DR, Mendel FC, Burton HW. Effect of a single 30-minute treatment of high voltage pulsed current on edema formation in frog hind limbs. Phys Ther. 1992;72(1):63-8. PMid:1728050.

6. Dolan MG, Graves P, Nakazawa C, Delano T, Hutson A, Mendel FC. Effects of ibuprofen and high-voltage electric stimulation on acute edema formation after blunt trauma to limbs of rats. J Athl Train. 2005;40(2):111-5. PMid:15970957.

7. Dolan MG, Mychaskiw AM, Mendel FC. Cool-water immersion and high-voltage electric stimulation curb edema formation in rats. J Athl Train. 2003;38(3):225-30. PMid:14608432.

8. Thornton RM, Mendel FC, Fish DR. Effects of electrical stimulation on edema formation in different strains of rats. Phys Ther. 1998;78(4):386-94. PMid:9555921.

9. Karnes JL, Mendel FC, Fish DR. Effects of low voltage pulsed current on edema formation in frog hind limbs following impact injury. Phys Ther. 1992;72(4):273-8. PMid: 1584859 .

10. Fish DR, Mendel FC, Schultz AM, Gottstein-Yerke LM. Effect of anodal high voltage pulsed current on edema formation in frog hind limbs. Phys Ther. 1991;71(10):72430, discussion 730-3. PMid:1946611.

11. Taylor K, Fish DR, Mendel FC, Burton HW. Effect of electrically induced muscle contractions on posttraumatic edema formation in frog hind limbs. Phys Ther. 1992;72(2):12732. PMid: 1549633.

12. Cosgrove KA, Alon G, Bell SF, Fischer SR, Fowler NR, Jones TL, et al. The electrical effect of two commonly used clinical stimulators on traumatic edema in rats. Phys Ther. 1992;72(3):227-33. PMid:1584856.

13. Reed BV. Effect of high voltage pulsed electrical stimulation on microvascular permeability to plasma proteins. A possible mechanism in minimizing edema. Phys Ther. 1988;68(4):491-5. PMid:2451258.

14. Mohr TM, Akers TK, Landry RG. Effect of high voltage stimulation on edema reduction in the rat hind limb. Phys Ther. 1987;67(11):1703-7. PMid:3499622.

15. Cook HA, Morales M, La Rosa EM, Dean J, Donnelly MK, McHugh P, et al. Effects of electrical stimulation on lymphatic flow and limb volume in the rat. Phys Ther. 1994;74(11):1040-6. PMid:7972365.

16. Evans TW. Review article: albumin as a drug — biological effects of albumin unrelated to oncotic pressure. Aliment Pharmacol Ther. 2002;16(Suppl 5):6-11. http://dx.doi. org/10.1046/j.1365-2036.16.s5.2.x. PMid:12423448

17. Michel CC, Kendall S. Differing effects of histamine and serotonin on microvascular permeability in anaesthetized rats. J Physiol. 1997;501(Pt 3):657-62. http://dx.doi. org/10.1111/j.1469-7793.1997.657bm.x. PMid:9218224

18. Omote K, Kawamata T, Nakayama Y, Yamamoto H, Kawamata M, Namiki A. Effects of a novel selective agonist for 
prostaglandin receptor subtype EP4 on hyperalgesia and inflammation in monoarthritic model. Anesthesiology. 2002;97(1):170-6. http://dx.doi.org/10.1097/00000542200207000-00024. PMid:12131119

19. Karges JR, Mark BE, Stikeleather SJ, Worrell TW. Concurrent validity of upper-extremity volume estimates: comparison of calculated volume derived from girth measurements and water displacement volume. Phys Ther. 2003;83(2):134-45. PMid:12564949.

20. Hargreaves K, Dubner R, Brown F, Flores C, Joris J. A new and sensitive method for measuring thermal nociception in cutaneous hyperalgesia. Pain. 1988;32(1):77-88. http:// dx.doi.org/10.1016/0304-3959(88)90026-7. PMid:3340425

21. Sluka KA, Bailey K, Bogush J, Olson R, Ricketts A. Treatment with either high or low frequency TENS reduces the secondary hyperalgesia observed after injection of kaolin and carrageenan into the knee joint. Pain. 1998;77(1):97102. http://dx.doi.org/10.1016/S0304-3959(98)00090-6. PMid:9755024

22. Gopalkrishnan P, Sluka KA. Effect of varying frequency, intensity, and pulse duration of transcutaneous electrical nerve stimulation on primary hyperalgesia in inflamed rats. Arch Phys Med Rehabil. 2000;81(7):984-90. http://dx.doi. org/10.1053/apmr.2000.5576. PMid:10896017

23. Sluka KA, Christy MR, Peterson WL, Rudd SL, Troy SM. Reduction of pain-related behaviors with either cold or heat treatment in an animal model of acute arthritis. Arch Phys Med Rehabil. 1999;80(3):313-7. http://dx.doi.org/10.1016/ S0003-9993(99)90143-0. PMid:10084440

24. Kaplan LA, Pesce AJ, Kazmierczak SC. Clinical Chemistry: theory, analysis and correlation. 4th ed. St Louis: Mosby; 2003.

25. Ramírez C, Russo TL, Delfino G, Peviani SM, Alcântara C, Salvini TF. Effect of tibiotarsal joint inflammation on gene expression and cross-sectional area in rat soleus muscle. Braz J Phys Ther. 2013;17(3):244-54. http://dx.doi. org/10.1590/S1413-35552012005000084. PMid:23802230.

26. Resende MA, Goncalves HH, Sabino GS, Pereira L, Francischi J. Reduction in analgesic effect from low-frequency transcutaneous electrical nerve stimulation in morphinetolerant rats. Rev Bras Fisioter. 2006;10(3):291-6. http:// dx.doi.org/10.1590/S1413-35552006000300007.

27. Salvemini D, Wang ZQ, Wyatt PS, Bourdon DM, Marino MH, Manning PT, et al. Nitric oxide: a key mediator in the early and late phase of carrageenan-induced rat paw inflammation. Br J Pharmacol. 1996;118(4):829-38. http:// dx.doi.org/10.1111/j.1476-5381.1996.tb15475.x. PMid:8799551

28. Santer V, Sriratana A, Lowther DA. Carrageenin-induced arthritis: V. A morphologic study of the development of inflammation in acute arthritis. Semin Arthritis Rheum. 1983;13(2):160-8. http://dx.doi.org/10.1016/0049-0172(83)900021. PMid:6673111

29. Mendel FC, Fish DR. New perspectives in edema control via electrical stimulation. J Athl Train. 1993;28(1):63-74. PMid:16558209.

30. Renkin EM, Joyner WL, Gustafson-Sgro M, Plopper G, Sibley L. Albumin extravasation rates in tissues of anesthetized and unanesthetized rats. J Appl Physiol (1985). 1989;66(5):205660. PMid:2745274.

31. Cicala C, Morello S, Alfieri A, Vellecco V, Marzocco S, Autore G. Haemostatic imbalance following carrageenan-induced rat paw oedema. Eur J Pharmacol. 2007;577(1-3):156-61. http://dx.doi.org/10.1016/j.ejphar.2007.08.007. PMid:17850787

32. Endo Y, Tabata T, Kuroda H, Tadano T, Matsushima K, Watanabe M. Induction of histidine decarboxylase in skeletal muscle in mice by electrical stimulation, prolonged walking and interleukin-1. J Physiol. 1998;509(Pt 2):587-98. http:// dx.doi.org/10.1111/j.1469-7793.1998.587bn.x. PMid:9575306

33. Watanabe M, Tabata T, Huh JI, Inai T, Tsuboi A, Sasaki $\mathrm{K}$, et al. Possible involvement of histamine in muscular fatigue in temporomandibular disorders: animal and human studies. J Dent Res. 1999;78(3):769-75. http://dx.doi.org/10 .1177/00220345990780030901. PMid:10096452

\section{Correspondence \\ Carolina Ramírez}

Universidade Industrial de Santander

Escola de Fisioterapia

Carrera 32 No. 29 - 31, Bucaramanga, Colômbia

E-mail: fisiocaro@yahoo.es 